Article

\title{
Taxonomy of Means and Ends in Aquaculture Production-Part 3: The Technical Solutions of Controlling N Compounds, Organic Matter, $P$ Compounds, Metals, Temperature and Preventing Disease
}

\author{
Bjorgvin Vilbergsson, Gudmundur V. Oddsson * and Runar Unnthorsson \\ Faculty of Industrial Engineering, Mechanical Engineering and Computer Science, Centre for Productivity, \\ Performance and Processes, University of Iceland, Hjardarhagi 6107, Reykjavik IS-107, Iceland; \\ bjoggivil@gmail.com (B.V.); runson@hi.is (R.U.) \\ * Correspondence: gvo@hi.is; Tel.: +354-5254635 \\ Academic Editors: Kevin B. Strychar and Giuliana Parisi \\ Received: 15 June 2016; Accepted: 24 October 2016; Published: 4 November 2016
}

\begin{abstract}
This is the third part of the taxonomy of technical solutions and treatment functions in aquaculture. This article builds on the premiss that the aquaculture production system can be viewed as a transformation process with three sets of functions, input, treatment and output. This work creates an overview of all of the technical solutions of treatment functions for the purpose of both design and further research. This is done with a comprehensive literature review where all technical solutions are identified and then categorized into a taxonomy. The result is a visual taxonomy of the treatment functions controlling $\mathrm{N}$ compounds, organic matter, $\mathrm{P}$ compounds, metals, temperature and preventing disease. A total taxonomy is finally presented where the results from Part 2 and Part 3 (this part) have been combined.
\end{abstract}

Keywords: aquaculture production; transformation view; treatment function; taxonomy; technical solution

\section{Introduction}

Answering the call to more fish production in an environmentally-friendly way will require an excellent understanding of how the aquaculture systems work and how each of the system's functions is solved. It is the purpose of this paper to create the next step in such an overview by finding all of the technical solutions and aligning them in a taxonomy. This is done to facilitate design information sharing, formalizing the design approach with the aim to, in the future, be able to create an aquaculture engineering design methodology. This research builds on Björnsdóttir et al. [1] and uses the transformation view of aquaculture production [1], that is input, treatment and output functions. The treatment functions are: controlling temperature, solids, dissolved gasses $\left(\mathrm{DO}\right.$ and $\left.\mathrm{CO}_{2}\right)$, $\mathrm{pH}$, nitrogen $(\mathrm{N})$ compounds, organic matter, phosphorus $(\mathrm{P})$ compounds, metals, disease outbreak along with the function of preventing diseases. The first part dealt with the treatment functions controlling $\mathrm{DO}$ and $\mathrm{CO}_{2}$, controlling solids and controlling $\mathrm{pH}$. This article deals with the rest, apart from controlling disease outbreak, which is out of the scope. Finding technical solutions for the input and output functions is not within the scope of this work.

The taxonomy for the technical solutions of the treatment functions part can be seen in Figure 1 . 


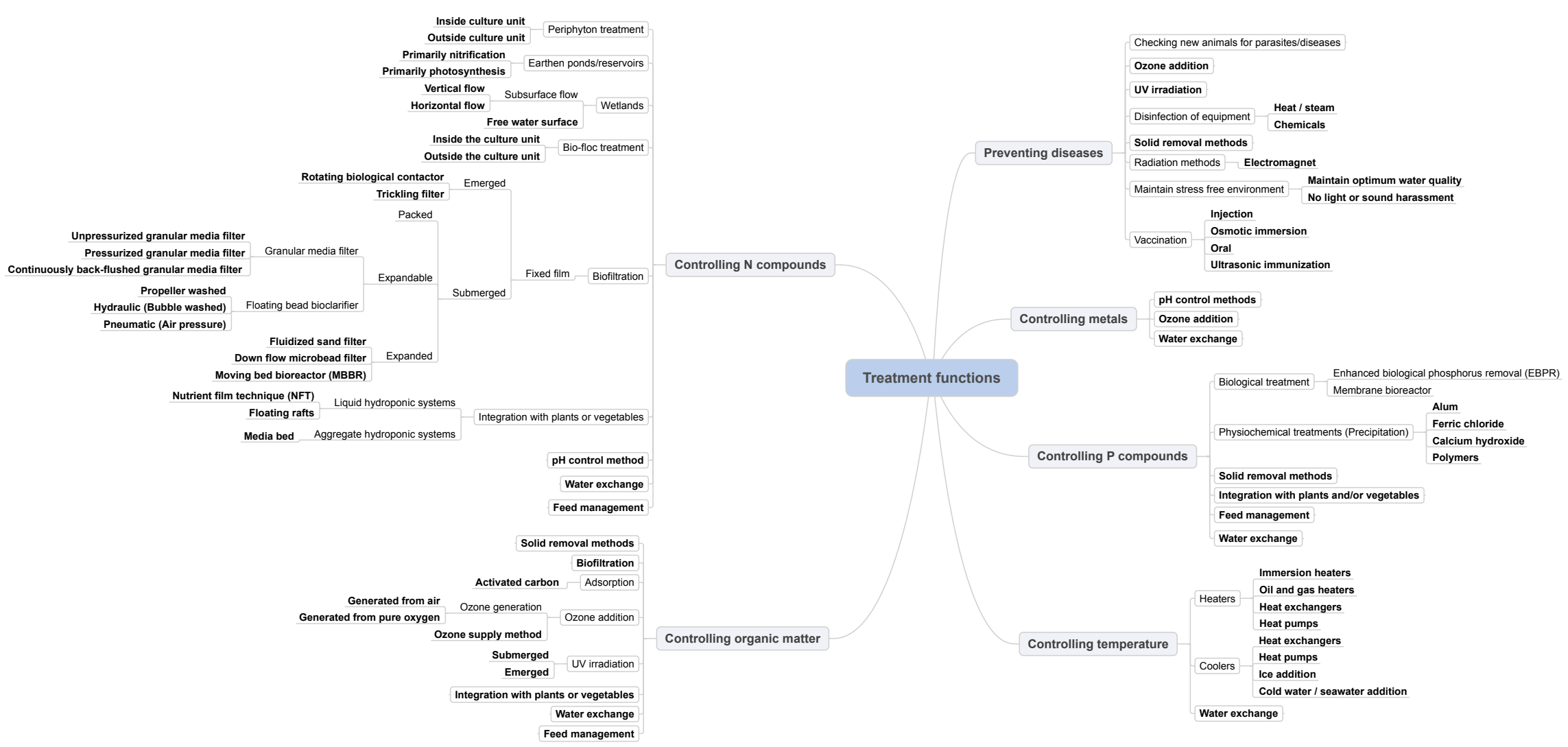

Figure 1. Taxonomy Part 2. 


\section{Materials and Methods}

This work is an extended synthesis of previous work into a taxonomy. This is done with a comprehensive literature review on the basis on of keywords generated in the previous work by Björnsdóttir et al. [1]. The scope, execution of the literature review and the synthesis are described in the next couple of sections.

\subsection{Scope}

The coverage of the article is limited to the functions identified by Björnsdóttir et al. [1]. Only a general description of the technical solutions is given here. Specific design attributes, often specific to each producer, are not covered. It should be clear that this paper only intends to create an overview of available solutions. Later, we plan to find how they can affect the treatment functions. Designing a system, or giving any indications on how a system should be designed, is out of the scope of this paper. The taxonomy is presented in two articles (Parts 2 and 3), where part of the technical solutions is described in this article and the other part in Part 2 [2]. A holistic view on this series of research is in Table 1.

Table 1. Overview of how the research is divided into articles.

\begin{tabular}{|c|c|}
\hline Article & Description \\
\hline Part 1: The functions [1] & $\begin{array}{l}\text { The transformational view of aquaculture is introduced, and the functions } \\
\text { are divided into input, treatment and output functions. There are } 5 \text { input } \\
\text { functions, } 10 \text { treatment functions and } 4 \text { output functions. Key parameters } \\
\text { used to control are identified and a nearly-exhaustive list of possible methods } \\
\text { of technical solutions is provided. The results are presented as a map. }\end{array}$ \\
\hline $\begin{array}{l}\text { Part 2: Technical solutions for } \\
\text { controlling solids, dissolved gasses } \\
\text { and } \mathrm{pH} \text { [2] }\end{array}$ & $\begin{array}{l}\text { The map of aquaculture production is used to find all possible technical } \\
\text { solutions for all of the methods in } 3 \text { treatment functions: controlling solids, } \\
\text { dissolved gasses and pH functions. The result is a partial taxonomy of } \\
\text { treatment functions from methods to technical solutions. }\end{array}$ \\
\hline $\begin{array}{l}\text { Part 3: Technical solutions for } \\
\text { controlling N compounds, organic } \\
\text { matter, P compounds, metals, } \\
\text { temperature and preventing disease } \\
\text { (this article) }\end{array}$ & $\begin{array}{l}\text { The map of aquaculture production is used to find all possible technical } \\
\text { solutions for all of the methods in } 6 \text { treatment functions, the controlling } \\
\mathrm{N} \text { compounds, organic matter, P compounds, metals, temperature and } \\
\text { preventing disease functions. The result is a partial taxonomy of treatment } \\
\text { functions from methods to technical solutions. A complete taxonomy of } \\
\text { technical solutions is presented. }\end{array}$ \\
\hline $\begin{array}{l}\text { Part 4: The mapping of technical } \\
\text { solutions onto multiple treatment } \\
\text { functions [3] }\end{array}$ & $\begin{array}{l}\text { The one-to-one relation between the technical solution and treatment } \\
\text { function is relaxed. The technical solutions from Parts } 2 \text { and } 3 \text { are analyzed, } \\
\text { and all of their effects on treatment functions are mapped out. Each relation } \\
\text { is put into one of three categories: intended, positive effect and negative } \\
\text { effect. The result is a quality-function-deployment presentation of the } \\
\text { interaction between solutions and functions. }\end{array}$ \\
\hline
\end{tabular}

\subsection{Literature Review}

This work is based on a literature review. Literature searches were carried out using The Web of Science $^{\mathrm{TM}}$ online service. A detailed description can be found in Vilbergsson et al. [2]. Searching The Web of Science ${ }^{\mathrm{TM}}$ using relevant search terms gave few publications that provided a general overview of available technical solutions [4]. Most were specific to certain types of components [5-7]. No taxonomy of technical solutions used in aquaculture was found. Further, no publications providing an overview of how these technical solutions influence other treatment functions were found. This obvious gap in the literature is what this paper begins to bridge. 


\subsection{Synthesis}

After the literature review, the material was grouped by the treatment functions and methods identified by Björnsdóttir et al. [1]. The methods were classified where relevant. The authors strove to use existing classification where available; however, that was not always possible. Some classification is suggested by the authors. Figure 2 explains the taxonomy setup, as well as how this paper adds to previous work.

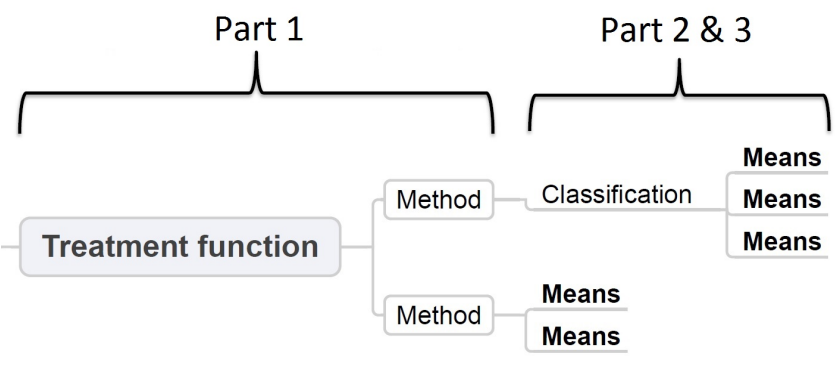

Figure 2. Scope of this paper.

The following section is Part 1 of the taxonomy of technical solutions.

\section{Resolving the Treatment Functions of Controlling N Compounds, Organic Matter, P Compounds, Metals, Temperature and Preventing Disease}

\subsection{Preventing Diseases}

Over 100 fish diseases exist and are caused by various microorganisms, such as bacteria, viruses, fungi and parasites. Diseases are mainly introduced to the system through the water, the fish or the equipment used, such as nets, baskets, gloves, etc. [8]. "Once diseases are introduced into a recirculating system, they are generally hard to control and treatment may disrupt the biofilter" [8]. Disinfection aims to reduce the amount of harmful microorganisms to acceptable levels and reducing the risk of the transfer of infectious diseases to fish. The main factors influencing disinfection efficiency are firstly water quality (suspended solids, UV water transparency, dissolved matter concentration), the concentration of disinfectant, time exposure, temperature and $\mathrm{pH}$ [9]. The treatment function preventing diseases covers all methods that are applied to prevent diseases in aquaculture systems. Methods used for disinfecting the culture water include: ozone addition, UV irradiation and solid removal methods. Other methods used to prevent diseases are: disinfecting equipment, maintaining a stress free environment, vaccination and checking new animals for parasites/diseases and radiation methods. This section describes the means used to prevent diseases within aquaculture systems.

\subsubsection{Inlet Control and Disinfection of Equipment}

Controlling the quality of all inlets (fresh water or seawater) is also vital. This can be done by using ground water from bore holes (seawater, brackish or fresh) to limit the amount of harmful substances in the inlet water. Disinfecting the water could be done if necessary, with regular samples taken and constant monitoring of the condition of the inlet. Disinfection of all equipment before use in the system or when moving equipment between tanks will reduce the likelihood of diseases spreading [8]. For disinfecting equipment (boots, nets, tanks, pumps, etc.) and buildings, heat or steam can be used [10]. Chemicals, such as chlorine, sodium hypochlorite and calcium hypochlorite, can be used to disinfect equipment, as well [11]. Other chemicals include: bromine, iodine, phenol and phenolic compounds, alcohols, heavy metals, soaps, synthetic detergents, quaternary ammonium compounds, hydrogen peroxide and various alkalis and acids. The partial taxonomy is shown in Figure 3. 


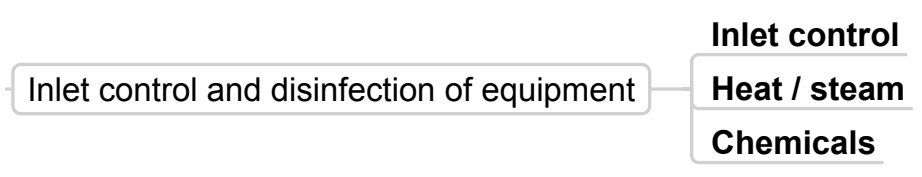

Figure 3. Partial taxonomy: Disinfection of equipment.

\subsubsection{Maintain Stress-Free Environment}

Stressed fish are more susceptible to diseases [8]. Water quality has a key influence on fish stress. However, stress can be produced by other factors, such as light, sound [8] or by handling. Therefore keeping the fish in a stress-free environment with low light or sound disturbance, water quality issues and minimizing any handling of the animal, such as grading, is very important for the prevention of diseases. The partial taxonomy is shown in Figure 4.

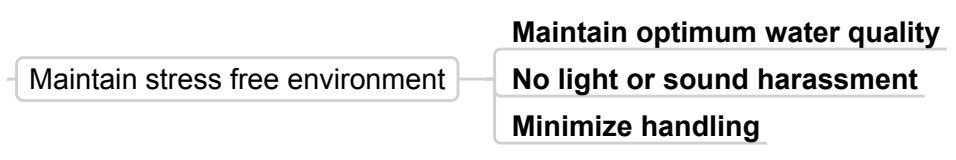

Figure 4. Partial taxonomy: Maintain stress-free environment.

\subsubsection{Vaccination}

Vaccines can protect aquatic animals against some viral and bacterial diseases. The effect is however dependent on the aquaculture species and diseases [12]. The means used to provide vaccine to fish are: injecting individual fish, oral administration, osmotic immersion and ultrasonic immunization (see Figure 5). Factors that need to be considered when vaccinating fish include minimizing stress and at what developmental stage the fish is.

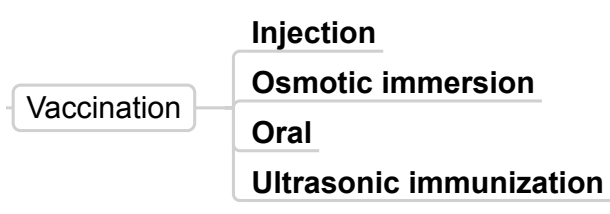

Figure 5. Partial taxonomy: Vaccination.

When injecting individual fish, the vaccine, mixed in an oil/water emulsion, is injected into the abdominal cavity. This stresses the animal and can only be applied after a certain developmental stage has been reached [13]. This can be done manually or automatically.

When using osmotic immersion, fish are immersed in a solution containing the vaccine. The vaccine is then absorbed through the lateral line and the gills [13]. The lateral line is a sensory organ located on both sides of the fish. This is less stressful than injection and can be applied at any developmental stage.

When administrating vaccination orally, the vaccine is mixed with the food. This method is non-stressing and can be used at any developmental stage of the fish [13].

In ultrasonic immunization vaccine is diluted in water/seawater, similar to osmotic immersion. The fish is immersed in the solution and exposed to ultrasound with a certain frequency and intensity [14].

\subsubsection{Solid Removal Methods}

Many microorganisms are attached to solids, so removing them from the system with the previously-mentioned solid removal methods will decrease the total number of microorganisms within the system. With a small enough mesh size $(<20 \mu \mathrm{m})$, some organisms can be filtered out, while membranes $(<1 \mathrm{~nm})$ can remove all types of microorganisms [10]. 


\subsubsection{Ozone Addition}

Ozone is an effective disinfectant against bacteria, parasites and viruses. Dosage and contact time has a big impact on its effectiveness. Disinfecting water in recirculating systems with ozone can be very expensive due to: (1) much higher ozone loading being required to overcome the organic demand and sustain a sufficient residual to achieve significant bacterial and viral reduction; and (2) the need to strip remaining ozone or residual oxidants from the water before it reaches the cultured species [15]. However, adding ozone at a lower rate just before entering the culture tanks could lower the risk of bacteria gill disease and the number of heterotrophic bacteria [15], as well as improve the overall water quality [16]. Ozone addition used for controlling organic matter is discussed in Section 3.4.2.

\subsubsection{UV Irradiation}

UV irradiation can be used to destroy ozone and inactivate microorganisms. Using UV as the main disinfectant process has increased in popularity for aquaculture water, as it is very effective for inactivating the pathogens Cryptosporidium and Giardia lamblia without forming any byproducts [17]. Water rich in particulate matter and other UV absorbing substances reduces the UV penetration and, therefore, its effectiveness. Treating the culture water with ozone followed by UV irradiation can result in "practically complete disinfection" of the total heterotrophic bacteria count [18]. The UV irradiation then both acts as a disinfectant, as well as destroying remaining ozone. UV lamps are placed either submerged in the water flow or above it (see Figure 6). By blowing air through the UV chamber, photozonewill be produced, which is an oxidant and works as a strong disinfectant [10].

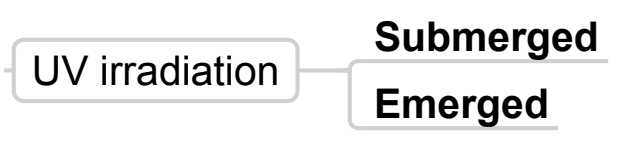

Figure 6. Partial taxonomy: UV irradiation.

\subsubsection{Radiation Methods}

Exposing fish (rainbow trout) to specific low frequency electromagnetic fields has "possible effects on growth performance, non-specific immunity and disease resistance" [19]. How to implement this in a practical way in aquaculture systems was not found.

\subsection{Controlling Temperature}

The temperature of the culture water is important. Each species has its temperature tolerance and range for optimum survival and growth. If the culture water temperature needs to be much higher than the inlet water temperature, lower water exchange rates could save on heating and cooling costs. Lekang [10] summarized the methods used in aquaculture for the heating and cooling of water. Various options exist, and choosing between them depends on the farm size and heating or cooling requirements. This section deals with the means used to manage temperatures within aquaculture systems.

\subsubsection{Heaters}

Immersion heaters use electricity to heat up the water. Inside the heater, water surrounds a heating element. The heating element is an electrical resistor transforming electrical energy into heat energy, heating up the water.

In oil and gas burners, water circulates in a combustion chamber where heat is released from either burning oil or gas.

Heat exchangers transfer energy from one medium to the other. They can both be used for heating or cooling. Heat energy gets transferred from the warmer liquid through the separating material to the colder liquid. Different types exist, such as plates and shell and tube exchangers (often used in heat pumps). Finally, tubes could be placed in open water body, such as a river, lake or ocean. 
Geothermal water can be used as the heat source for aquaculture utilizing heat exchangers to heat up the culture water.

Heat pumps are used to "pump" heat in the opposite direction of spontaneous heat flow. A heat pump consists of an evaporator, compressor, condenser and expansion valve. A working fluid circulates these components, transferring heat from the surroundings of the evaporator to the surroundings of the condenser. In the evaporator, the working fluid (in the low pressure gas phase) receives heat from the surroundings (which could be air, any water body or the ocean). Then, the compressor increases the pressure of the working fluid before it enters the condenser. In the condenser, the heat transfers from the working fluid to the surrounding (culture water here). Finally, an expansion valve lowers the pressure of the liquid before it enters the evaporator again. Heat pumps are also used for cooling (i.e., refrigerators). The evaporator then extracts heat from the culture water and releases it to a recipient body (air, water, ocean) through the condenser.

Composite heating systems are systems utilizing more than one heating technique and are commonly used in aquaculture.

\subsubsection{Coolers}

In addition to heat exchangers and heat pumps, ice can be used for quick cooling. Other options include direct mixing of colder water or seawater. Trickling filters can also be used for evaporation cooling in warm climates [20].

\subsection{Controlling N Compounds}

Nitrogen is a nutrient essential to all living organisms. The main sources of nitrogen wastes in aquaculture are metabolic waste from fish and uneaten or undigested feed [5]. Fish also discharges various nitrogenous waste products that decompose into toxic compounds, such as ammonia and nitrite. These compounds are toxic to fish and therefore of great interest in intensive recirculating aquaculture systems [21]. The treatment function controlling $\mathrm{N}$ compounds deals with methods used to maintain the concentration of $\mathrm{N}$ compounds below certain toxicity levels. Those methods are: periphyton treatment, bio-floc treatment, earthen ponds/reservoirs, wetlands, biofiltration, $\mathrm{pH}$ control methods, integration with plants/vegetables, water exchange and feed management. This section describes the means used to control $\mathrm{N}$ compounds.

\section{Nitrification}

Nitrification is a major biological process used in aquaculture waste water treatment [5]. In the nitrification process, ammonia is oxidized to nitrite and less toxic nitrate [21]. To prevent accumulation of nitrate in the system, water exchange or denitrification process is needed [22]. Nitrification is an aerobic process, therefore consuming oxygen, while denitrification is an anaerobic process converting nitrate into nitrogen gas [21]. The nitrification process consumes approximately $0.15-0.19 \mathrm{~kg}$ of sodium bicarbonate $/ \mathrm{kg}$ feed [23]. This alkalinity consumption needs to be compensated with base addition to prevent lowering of the $\mathrm{pH}$ [24]. Within a nitrification system, the overall $\mathrm{O}_{2}$ consumption is $4.6 \mathrm{mg}$ for everymg of total ammonia nitrogen (TAN) removed while at the same time producing $5.9 \mathrm{mg}$ of $\mathrm{CO}_{2}$ for every mg of TAN [25]. It has been shown that the nitrification accounts for a large percentage of the system dissolved $\mathrm{CO}_{2}$ production, and that needs to be accounted for in the system design [25].

\subsection{1. $\mathrm{pH}$ Control Methods}

Managing the $\mathrm{pH}$ in the system is vital. The $\mathrm{pH}$ controls the ratio of un-ionized ammonia $\left(\mathrm{NH}_{3}\right)$ and ionized ammonia $\left(\mathrm{NH}_{4}^{+}\right)$formed. It also has a major effect on the performance of nitrifying bacteria in biofilters [24]. Several methods to manage $\mathrm{pH}$ exist and are discussed in Vilbergsson et al. [2]. 


\subsubsection{Biofiltration}

Biofilters use media with a high specific surface area (i.e., surface per unit volume) to allow for the growth of nitrifying bacteria [21] and an appropriate void ratio to reduce clogging and improve hydraulic performance [20]. Nitrification biofilters are fixed film filters and can be classified as either emerged or submerged [7]. In Figure 7, a modified classification from Malone and Pfeiffer [7] is presented. Various designs exist, but here, we cover the most common ones found in the literature.

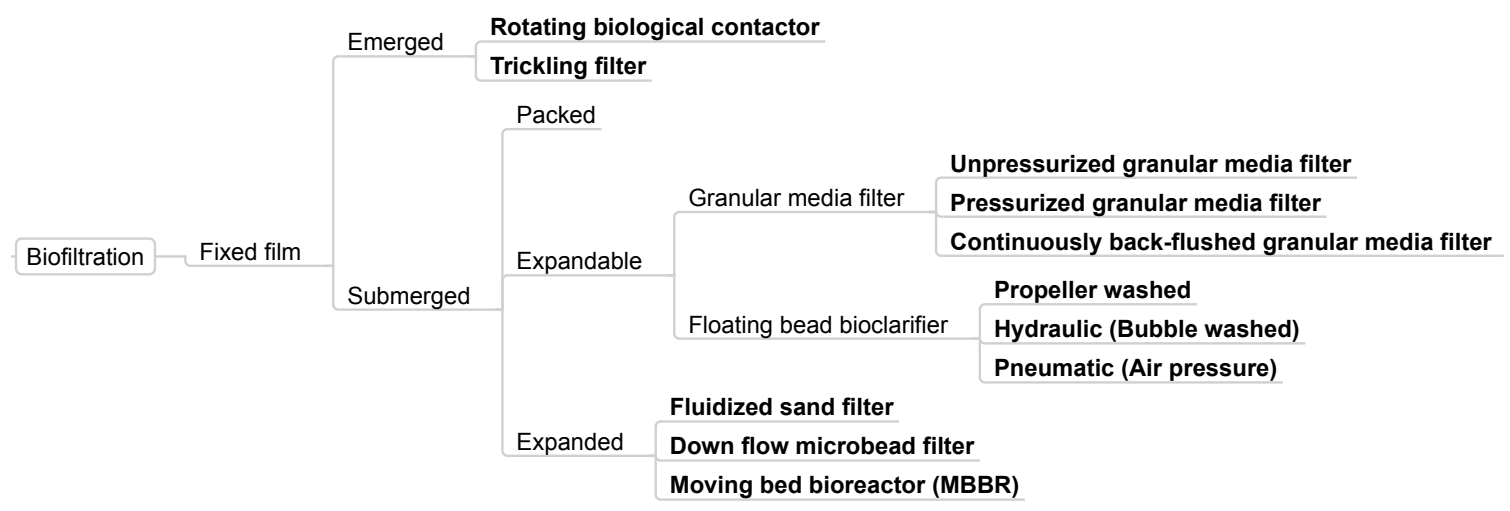

Figure 7. Partial taxonomy: Biofiltration.

\section{Emerged Filters}

In a rotating biological contactor ( $\mathrm{RBC}$ ), the biofilm supporting media is attached to a partially-submerged horizontal shaft that rotates, temporarily lifting the media out of the process water. As the media contacts the air, $\mathrm{CO}_{2}$ is stripped from the water and oxygen is supplemented [26]. The RBC can be rotated using compressed air [27], water or simply a shaft motor [26]. The degree of $\mathrm{RBC}$ medium submergence influences the performance. RBC that operates at submergence around $70 \%-90 \%$ is called a submerged biological contactor; aeration decreases, while a larger media volume is available [28]. Several stages can be used. By recycling part of the process water from the last stage to the first, studies show improvements in $\mathrm{COD}, \mathrm{BOD}_{5}$ and ammonia removal and increased $\mathrm{DO}$ concentrations [29] along with denitrification of the recirculation water [28]. Ayoub and Saikaly [29] demonstrated that step-feed improved $\mathrm{NH}_{3}-\mathrm{N}$ and $\mathrm{COD}$ removal rates and resulted in higher $\mathrm{DO}$ values.

Trickling filters resemble packed columns. In trickling filters, water enters the unit from above and trickles down over a thin biofilm on the packing media. Water needs to be well distributed at the top to achieve good utilization of the filter volume. This can be accomplished using a moving arm, perforated screen or a nozzle [20]. The packing media are constructed so that they create a cross-flow, vertical flow or random flow of water through the filter [20]. The height of the packed media can vary between 0.6 and $4.5 \mathrm{~m}$ [30]. Ventilation of the filter is vital. To ensure good ventilation, the filter has either an open bottom or closed bottom equipped with a fan for forced ventilation. With controlled ventilation (ratio of air to water flow needs to be around 10), trickling filters can also provide degassing or CO2 stripping and even evaporation cooling in warm climates [20]. Water exiting the trickling filter is usually close to DO saturation [30].

\section{Submerged Filters}

Malone and Pfeiffer [7] classified submerged filters further as packed, expandable and expanded filters.

Packed bed filters are filters where the bed medium is not expandable. They are not very effective at solid removal equipment, and the biofilm is controlled by endogenous respiration [7]. Water flows either from the top or from the bottom through the biofilm-covered packed bed. 
Expandable bed filters are filters where the media bed is occasionally expanded in order to remove trapped solids and biofilm growth. Granular media filters (discussed in Vilbergsson et al. [2]) can be used as nitrification filters ([10] p. 127). Floating bead bioclarifiers (discussed in Vilbergsson et al. [2]) are categorized as expandable bed filters. They provide nitrification in addition to solid removal and, if operated in anaerobic conditions, denitrification [31].

Expanded bed filters are filters where the media are constantly kept suspended by hydraulic or pneumatic means [7]. Summerfelt [32] described the design and management of fluidized sand biofilters (FSB). The sand bed (it can be other material) is kept fluidized within a tank by an upward flow of water entering at the bottom of the bed. The design of the flow distribution mechanism at the base of the unit is critical, not only to maintain well-distributed water flow, but also to prevent clogging, fouling and loss of sand [32]. A fluidized sand filter can also be used for heterotrophic denitrification [33].

Downflow microbead filters provide nitrification. They are "a combination of trickling and granular type biological filters" [34]. Water is distributed from the top and trickles down through a floating media bed into a retention vessel; from there, water leaves the filter by gravity. The media used are highly buoyant polystyrene beads between 1 and $3 \mathrm{~mm}$ in diameter, hence microbeads [34,35]. The depth of the bead bed is limited to around $50 \mathrm{~cm}$ [34]. The media can be allowed to float freely in the retention vessel or it can be forced to be submerged by the water distribution plate at the top [34], simply by raising the water level in the retention vessel, for example. By allowing space between the media and the water spray, gas stripping can be forced [34]. An air blower and ventilation then need to be installed.

In a moving bed bioreactor (MBBR), water is fed into a reactor containing a bed of plastic media, which is kept suspended either by agitation from air, for the aerobic process (nitrification), or by mechanical stirring (propeller), or a circulating pumping (careful placement of the inlet and outlet) for anoxic and anaerobic processes [36]. It can be totally closed, capturing exhaust gas, or open. The media size in particular ranges from 0.5 to $1.5 \mathrm{~cm}$ with a density around $0.92-0.98 \mathrm{~g} / \mathrm{cm}^{3}$ [37].

\subsubsection{Integration with Plants/Vegetables}

Aquaponics are the integration between aquaculture and hydroponics. In hydroponics, plants are grown in soilless medium where all of the nutrients are delivered dissolved in water. Hydroponics strip the process water of nutrients, such as nitrates and phosphorus [38,39]. They can also remove dissolved organic matter in recirculating aquaponic systems [40]. Some aquaponics systems collect suspended solids and facilitate the conversion of the excrement from the cultured species to more available forms for the plants before entering the hydroponic bed. A biofilter is then placed before the hydroponic bed to convert ammonia to nitrate, which is then taken up by the plant roots [39]. The nutrients' removal efficiency is dependent on various factors, such as plant species and plant age [41], nutrient concentration and the subsystem [39]. Hydroponics can be considered either as liquid hydroponic systems or aggregated hydroponic systems [38], as seen in Figure 8. Liquid hydroponic systems use the nutrient film technique (NFT) or floating rafts, while the aggregate hydroponic system uses some sort of media bed [38].

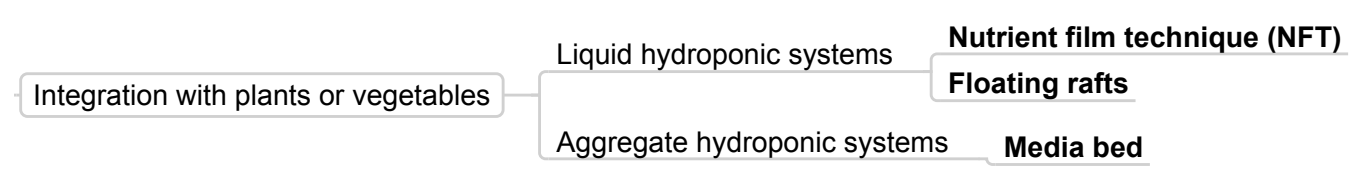

Figure 8. Partial taxonomy: Integration with plants/vegetables. 
The integration of fish and plant species is important in aquaponic systems. Plant selection depends on the intensity of the aquaculture system and, therefore, available nutrient levels in the effluent for plant uptake [38]. Both the crop and cropping method have considerable impacts on nutrient removal [41]. The plant to fish ratio, hydraulic loading rate, DO and water temperature all influence the overall performance of the system [42]. Lennard and Leonard [39], comparing NFT, floating rafts and media beds, found the DO of the process water to decrease over all three types of hydroponic beds.

\section{Liquid Hydroponic Systems}

In NFT systems, plants are placed in a narrow channel or gutter and a thin film of the nutrient-rich process water flows over the bare roots of the plants. The channel has a slight slope to sustain constant water flow and prevent ponding. In floating raft systems, the plants are supported by a raft, such as polystyrene sheets [40], which floats on the surface of the nutrient-rich process water with the plant roots expanded in the water. The floating rafts can be placed in the culture tank or in a separate tank. Solids can accumulate on the plant roots, prohibiting oxygen and nutrient uptake.

\section{Aggregated Hydroponic Systems}

The media bed is contained in a holding vessel, such as a bag, trench, pipe or bench. Media include gravel, sand, expanded clay, perlite, peat, sawdust, etc. Plant roots and media also provide surface area for nitrifying bacteria and solid capture [39,42]. The process water can be fed directly to the hydroponic bed, which then removes dissolved solids and facilitates nitrification. The media bed can be (but not necessarily) alternately flooded and drained, improving aeration, which benefits nitrifying and heterotrophic bacteria and plant roots [38].

\subsubsection{Wetlands}

Constructed wetlands can be used for water treatment in recirculation systems to reduce total suspended solids (TSS), TAN and P [43]. Constructed wetlands can have gravel or rock beds, therefore having a subsurface flow (SSF) [43], or a soil-based bed, which is then flooded; so-called free water surface (vegetated submerged bed) [44]. Figure 9 displays the partial taxonomy. Plants of various types serve, among other organisms, the purpose of removing nutrients ( $\mathrm{N}$ and $\mathrm{P}$ ) from the processing water for reuse [45]. This is done via nitrification and plant uptake [45]. Microorganisms occurring in constructed wetlands can inactivate pathogenic microorganisms in the system, given adequate retention time [10]. The water flow through SSF wetland can be vertical [46] or horizontal $[43,44]$. SSF might require pre-treatment to prevent TSS accumulation [47].

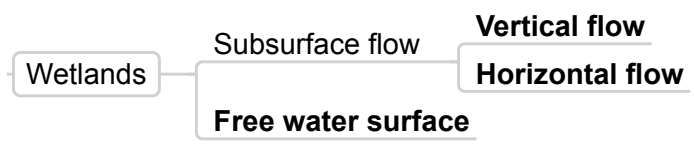

Figure 9. Partial taxonomy: Wetlands.

\subsubsection{Earthen-Ponds/Reservoirs}

In Figure 10, the partial taxonomy is given of earthen-ponds/reservoirs. $\mathrm{N}$ removal is primarily done either by nitrification or photosynthesis (phytoplankton uptake). Phytoplankton, such as algae, can be used as a supplement feed source for animal cultures [48]. Here, water recirculates between the culture unit and an earthen treatment pond/reservoirs. Water quality is controlled by a combination of mechanical and natural processes that take place in the pond. Waste assimilation, nutrient recycling and food production are all combined in the earthen pond [5]. Algae retains phosphorus [48], and sediment in ponds can have a good $\mathrm{P}$ absorption capacity [49]. Ammonia can be removed from the culture unit in two ways, either by water exchange or nitrification within the unit [49]. In the 
latter case, the pond serves as a denitrification unit (sediment important). The ratio of unit area to treatment pond area and the hydraulic retention time need to be determined in terms of desired ammonia removal [49]. Ammonia transformation in ponds can be carried out by phytoplankton uptake, immobilization and nitrification. These processes are dependent on various variables, including dissolved oxygen, organic particle concentration, sunlight, C:N ratio and temperature [49]. Some of those variables can be mechanically manipulated, while others are dependent on other input functions or the surrounding environment.

\begin{tabular}{|l|l} 
Earthen ponds/reservoirs & Primarily nitrification \\
\hline Primarily photosynthesis
\end{tabular}

Figure 10. Partial taxonomy: Earthen-pond/reservoirs.

\subsubsection{Bio-Floc Treatment}

Bio-floc treatment is a co-culture of heterotrophic and nitrifying bacteria and algae grown in suspended flocs usually within the culture unit. These flocs take up particulate organic matter and nitrogen waste from the fish/shellfish, decreasing ammonium concentrations within the system, and create a supplementary protein source for the fish or shellfish [5,50]. A bio-floc system is designed to use little or no water exchange. This causes nutrients that cannot be lost atmospherically, such as phosphorus and phosphate, to accumulate in the system [51]. Phosphorus that is retained within particulate matter flocculates and can be eaten by the cultured species. The heterotrophic bacteria need organic carbon to immobilize nitrogen; carbohydrates therefore need to be added to the system.

Carbon can be supplied either directly as an additional organic carbon source (glucose, glycerol, etc.) or the feed composition can be manipulated [52]. This process is aerobic, therefore lowering the dissolved oxygen content of the water. The bio-floc can be grown outside the culture unit in an "external bio-flocs reactor" and then redirected to the unit as feed [52]. This way, sensitive species are protected from DO variations. The consumption of alkalinity by heterotrophic and nitrifying bacteria present in bio-floc causes a reduction in alkalinity and $\mathrm{pH}$ in the system [53]. The taxonomy (Figure 11) classifies bio-floc either as inside or outside the culture unit.

$\begin{array}{ll}\text { Bio-floc treatment } & \text { Inside the culture unit } \\ \text { Outside the culture unit }\end{array}$

Figure 11. Partial taxonomy: Bio-floc treatment.

\subsubsection{Periphyton Treatment}

Periphyton is a mixture of plants and animal organisms that are attached to an artificial substrate in the culture system. These organisms trap and process suspended organic matter and utilize nutrients in the water via photosynthesis. It therefore produces $\mathrm{O}_{2}$, removes $\mathrm{CO}_{2}$ and potentially provides extra food for the cultured species [54]. It could also help manage the $\mathrm{pH}$ [5].

Crab et al. [5] concluded that a periphyton treatment in intensive aquaculture would not be feasible. Beveridge et al. [54], however, reflected, although not utilized so far in intensive aquaculture, that periphyton treatment could potentially be used to some degree in such systems. For instance, in fingerling production or by stocking two fish species, high-value carnivorous fish can utilize feed, while another species is able to utilize the periphyton [54]. This can be either inside the culture unit or in a separate unit within the system [55]. In the taxonomy (Figure 12), the periphyton treatment is classified as either inside or outside the culture unit. 


\begin{tabular}{ll} 
Periphyton treatment & Inside culture unit \\
\hline Outside culture unit
\end{tabular}

Figure 12. Partial taxonomy: Periphyton treatment.

\subsection{Controlling Organic Matter}

Organic matter consists of impurities in the culture water that originate from feeding and metabolic waste. Organic matter can be split into solid and dissolved organic matter. The function controlling organic matter covers all methods used to remove or control the accumulation of organic matter [56]. This section deals with the means used to carry out the treatment function controlling organic matter. Some methods used to solve other treatment functions also solve this one, as displayed in [57]. These methods are: solid removal methods, biofiltration, integration with plants/vegetables, water exchange and feed management. Only the methods of adsorption, ozone addition and UV irradiation have not been discussed earlier in this thesis.

\subsubsection{Solid Removal Methods}

Solid organic matter can be removed using the solid removal techniques covered in Vilbergsson et al. [2].

\subsubsection{Ozone Addition}

Ozone can improve multiple water quality indicators, including oxidizing toxic nitrite to nitrate [58], removal of organic compounds by oxidizing dissolved organic matter and improving flocculation of fine and colloidal particulates; that results in better particle removal via settling, filtration [59] or foam fractionation [58].

To apply ozone within aquaculture systems, an ozone generator is required. Ozone gas is unstable and, therefore, needs to be produced on site from either air or pure oxygen. Ozone can then be supplied to the water by the same techniques used for oxygenation (Figure 13 and see Vilbergsson et al. [2]). It needs to be taken into considerations that the equipment is made of ozone-resistant material and that it is leak free, due to the high oxidizing properties and toxicity of ozone [60]. In brackish and seawater systems, ozone reacts with bromide ions and is transformed into total residual oxidants (TRO). These residual oxidants are relatively stable and toxic to fish and shellfish. Specific methods for measuring and monitoring TRO are necessary, such as DPD colorimetric analysis [60]. Residual ozone and other oxidants cannot come in contact with the cultured species due to its toxicity. In seawater application, a treatment unit for removal of residual bromine has to be included [60]. To remove excess ozone, a retention chamber can be added to allow time for normal ozone decay, water can be passed through a forced-ventilation column, by air-stripping or it can be destroyed using UV irradiation [59]. Activated carbon filtration or the addition of reducing agent will also reduce or eradicate residual ozone and other oxidants [60]. UV irradiation can be used to destroy ozone [59] and inactivate microorganisms [61]. Ozone is destroyed at wavelengths between 250 and $260 \mathrm{~nm}$. The required UV intensity (quantity of energy transmitted) to deliver the desired UV dose through the water to the target (microorganism or ozone) needs to be established [62].

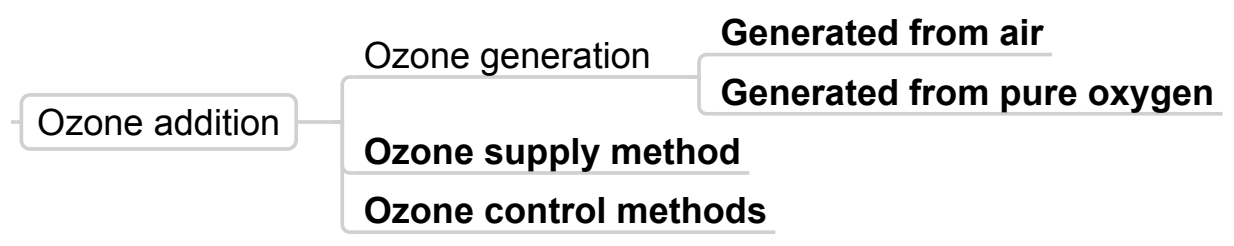

Figure 13. Partial taxonomy: Ozone addition. 


\subsubsection{Adsorption Process}

Adsorption onto activated carbon can be used for the removal of dissolved organic carbon along with therapeutants [63]. Adsorption is where dissolved compounds accumulate on a solid due to intermolecular attraction forces. Activated carbon is a good adsorbent and has a high surface area per unit weight. The adsorption capacity depends on the accessibility of the organic molecules to the inner surface of the adsorbent, the pore texture, surface chemistry and mineral matter content [64].

\subsubsection{Biofiltration}

In biofilters (Section 3.3.2), dissolved organic matter can be oxidized therefore reducing its concentration [65]. They are however not effective at removing particulate organic matter [66], and in too much quantity, they can cause problems, such as clogging [20].

\subsection{Controlling P Compounds}

Phosphorus $(\mathrm{P})$ is fundamental to all life. In aquaculture, it enters the culture unit with feed. Not all phosphorus provided is utilized by the cultured species and is retained in the system either as uneaten feed or excrement. With time, the phosphorus leaches from solids (feed or excrement particles) and becomes dissolved in the culture water. Disintegration and bacterial degradation of solids, temperature and incubation time all influence the amount of phosphorus lost from the solid form to dissolved [67]. As solid phosphorus stays longer in the system, goes though equipment, etc., more gets dissolved into the culture water, making it more difficult to remove. Total phosphorus is the sum of solid phosphorus and the dissolved phosphorus in the system. Thirty to eighty four percent of the total phosphorus is in the solid form, while the rest is dissolved [6]. Phosphorus is not toxic to fish. However, in high quantities, it can lead to harmful cyanobacteria blooms in the culture system [51]. Furthermore, excessive discharge of phosphorus to receiving waters may lead to eutrophication, resulting in water quality degradation.

The treatment function controlling $\mathrm{P}$ compounds deals with the methods used to maintain phosphorus levels in the system within acceptable limits. This section describes the means used to carry out the treatment function controlling P compounds. Several methods are used to control P compounds; physicochemical treatment, solid removal methods, integration with plants and/or vegetables along with feed management and water exchange. The sludge biological treatment is used to minimize the phosphorus released into the environment. Sludge treatment is however not within the scope of this project.

\subsubsection{Solid Removal Methods}

To remove phosphorus in solid form, solid removal methods, such as sedimentation, filters (mechanical, bead), hydrocyclones and flotation, are used. These methods are covered in Vilbergsson et al. [2].

\subsubsection{Physicochemical Treatments}

In physicochemical treatment, chemicals are added to increase the coagulation/flocculation of dissolved phosphorus. The phosphorus coagulates into the sold form and can be removed by solid removal methods. Chemicals, such as alum, ferric chloride and calcium hydroxide, can be used to coagulate dissolved phosphorus [68]. See Figure 14. Polymers can also be used, but are not as effective at removing phosphorus [69]. However, using polymers in conjunction with other chemicals, such as alum [69] or calcium hydroxide [68], shows much better results. 


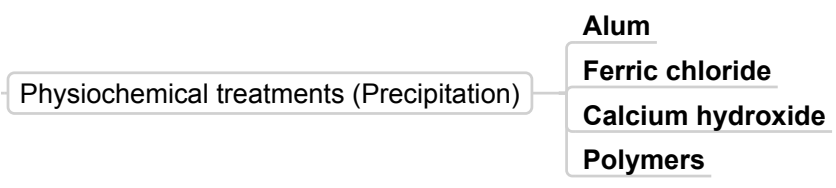

Figure 14. Partial taxonomy: Physicochemical treatments.

\subsection{Controlling Metals}

Metal compounds can become toxic to the cultured species, the environment or the consumer. This includes both heavy metals (cadmium, copper, etc.) and other metals (aluminum, iron, etc.). Metals can originate from the corrosion of pipes and fittings or from feed [70]. In systems with low water exchange, heavy metals, such as zinc, copper, cadmium, cobalt and manganese, accumulate in the system [70,71]. Cadmium, copper and zinc should be observed closely in recirculating systems [70]. This section describes the means that can be used to carry out the treatment function controlling metals. Methods to prevent metals from becoming toxic to the cultured species in aquaculture systems are $\mathrm{pH}$ control methods, ozone addition and water exchange.

\subsection{1. $\mathrm{pH}$ Control Methods}

$\mathrm{pH}$ control methods (discussed in Vilbergsson et al. [2]) can be used in the control of metals in aquaculture. By increasing the alkalinity and hardness of the culture water, the toxicity of metals, such as copper, cadmium and zinc, can be reduced [70]. Shell-sand filters and seawater addition can lower the labile (inorganic) aluminum in the culture water [72]; silica lye can also be used to decrease the toxicity of aluminum [10], and calcium and magnesium decrease the toxicity of dissolved metals [11].

\subsubsection{Ozone Addition}

Ozone addition (the method covered in Section 3.4.2) can be used to "significantly" lower dissolved copper and iron in systems with a low water exchange rate, such as RAS. The concentration of dissolved zinc can be lowered, as well [23].

\section{Taxonomy of the Technical Solutions of the Treatment Functions}

All of the technical solutions found, both in this article and the previous one [2], can be put together into a single taxonomy of technical solutions. That taxonomy is shown in Figure 15. 


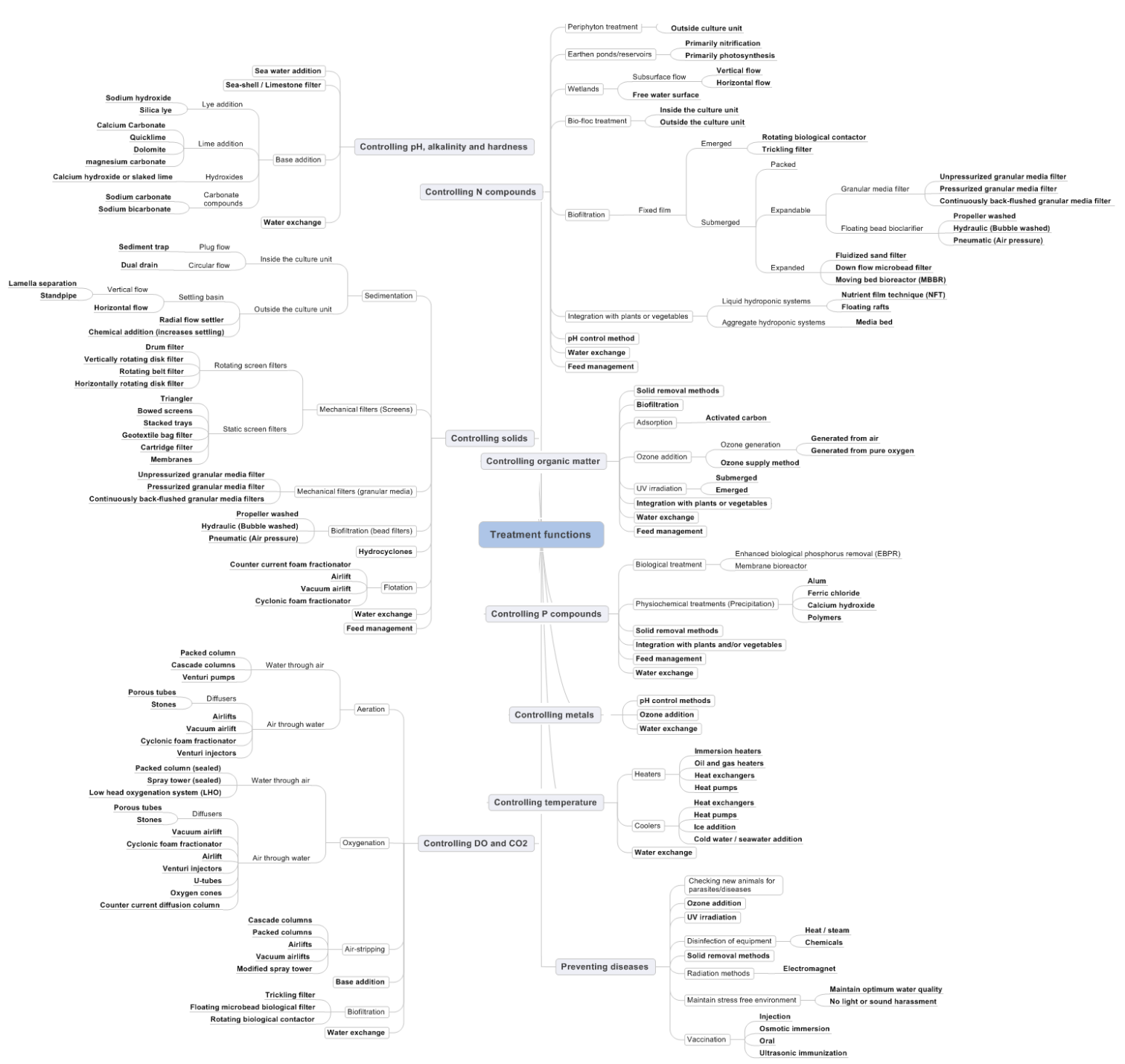

Figure 15. Taxonomy of the technical solutions of the treatment functions. 


\section{Discussion}

The taxonomy of the technical solutions that solve the treatment function, one or many, is now complete. This overview allows us to realize how treatments are solved in aquaculture production and leads to the next step. It seems that one technical solution is solving only one treatment function. We of course know that it is not so. The technical solutions often solve or partly solve more that one treatment function. The solution might even have a negative effect on other areas of the aquaculture production. To be able to generate an aquaculture design methodology, this interaction or overlap has to be laid out. That is done in our next article [3]. Future research that is made possible with the taxonomy and its consequent interaction matrix [3] include an aquaculture engineering design methodology, a systemic view on how aquaculture production behaves, the making of design aids for new designs and the application of optimization on a system level.

Author Contributions: Gudmundur V. Oddsson and Bjorgvin Vilbergsson conceived of and designed the work. Bjorgvin Vilbergsson performed the systematic literature review. Bjorgvin Vilbergsson analyzed the data. Gudmundur V. Oddsson and Runar Unnthorsson structured the paper and reviewed the results. All authors wrote the paper.

Conflicts of Interest: The authors declare no conflict of interest.

\section{References}

1. Björnsdóttir, R.; Oddsson, G.V.; Thorarinsdottir, R.; Unnthorsson, R. Taxonomy of means and ends in aquaculture production-Part 1: The functions. Water 2016, 8, 319.

2. Vilbergsson, B.; Oddsson, G.V.; Unnthorsson, R. Taxonomy of means and ends in aquaculture production-Part 2: The technical solutions of controlling solids, disolved gasses and $\mathrm{pH}$. Water 2016, 8, 387.

3. Vilbergsson, B.; Oddsson, G.V.; Unnthorsson, R. Taxonomy of means and ends in aquaculture production-Part 4: The mapping of technical solutions onto multiple treatment function. Water 2016, 8, 387.

4. Losordo, T.M.; Masser, M.P.; Rakocy, J. Recirculating Aquaculture Tank Production Systems-A Review of Component Options; SRAC Publication: Stoneville, MS, USA, 1999.

5. Crab, R.; Avnimelech, Y.; Defoirdt, T.; Bossier, P.; Verstraete, W. Nitrogen removal techniques in aquaculture for a sustainable production. Aquaculture 2007, 270, 1-14.

6. Cripps, S.J.; Bergheim, A. Solids management and removal for intensive land-based aquaculture production systems. Aquac. Eng. 2000, 22, 33-56.

7. Malone, R.F.; Pfeiffer, T.J. Rating fixed film nitrifying biofilters used in recirculating aquaculture systems. Aquac. Eng. 2006, 34, 389-402.

8. Masser, M.; Rakocy, J.; Losordo, T. Recirculating Aquaculture Tank Production Systems-Management of Recirculating Systems; SRAC Publication: Stoneville, MS, USA, 1999.

9. World Health Organization. Water Treatment and Pathogen Control: Process Efficiency in Achieving Safe Drinking Water; Technical Report; World Health Organization: London, UK, 2004.

10. Lekang, O. Aquaculture Engineering; Blackwell Publishing Ltd.: Oxford, UK, 2007.

11. Timmons, M.B.; Ebeling, J.M. Recirculating Aquaculture, 2nd ed.; Cayuga Aqua Ventures: Ithaca, NY, USA, 2010.

12. Stickney, R.R. Aquaculture: An Introductory Text; CAB International: Cambridge, MA, USA, 2005.

13. Dunn, E.J.; Polk, A.; Scarrett, D.J.; Olivier, G.; Lall, S.; Goosen, M.F. Vaccines in aquaculture: The search for an efficient delivery system. Aquac. Eng. 1990, 9, 23-32.

14. Zhou, Y.C.; Wang, J.; Zhang, B.; Su, Y.Q. Ultrasonic immunization of sea bream, Pagrus major (Temminck \& Schlegel), with a mixed vaccine against Vibrio alginolyticus and V. anguillarum. J. Fish Dis. 2002, 25, 325-331.

15. Bullock, G.L.; Summerfelt, S.T.; Noble, A.C.; Weber, A.L.; Durant, M.D.; Hankins, J.A. Ozonation of a recirculating rainbow trout culture system I. Effects on bacterial gill disease and heterotrophic bacteria. Aquaculture 1997, 158, 43-55.

16. Summerfelt, S.T.; Hankins, J.A.; Weber, A.L.; Durant, M.D. Ozonation of a recirculating rainbow trout culture system II. Effects on microscreen filtration and water quality. Aquaculture 1997, 158, 57-67.

17. Mamane, H.; Colorni, A.; Bar, I.; Ori, I.; Mozes, N. The use of an open channel, low pressure UV reactor for water treatment in low head recirculating aquaculture systems (LH-RAS). Aquac. Eng. 2010, 42, 103-111. 
18. Summerfelt, S.T.; Sharrer, M.J.; Tsukuda, S.M.; Gearheart, M. Process requirements for achieving full-flow disinfection of recirculating water using ozonation and UV irradiation. Aquac. Eng. 2009, 40, 17-27.

19. Nofouzi, K.; Sheikhzadeh, N.; Mohamad-Zadeh Jassur, D.; Ashrafi-Helan, J. Influence of extremely low frequency electromagnetic fields on growth performance, innate immune response, biochemical parameters and disease resistance in rainbow trout, Oncorhynchus mykiss. Fish Physiol. Biochem. 2015, 41, 721-731.

20. Eding, E.; Kamstra, A.; Verreth, J.; Huisman, E.; Klapwijk, A. Design and operation of nitrifying trickling filters in recirculating aquaculture: A review. Aquac. Eng. 2006, 34, 234-260.

21. Tidwell, J. Aquaculture Production Systems; Wiley-Blackwell: Oxford, UK, 2012.

22. Hamlin, H.; Michaels, J.; Beaulaton, C.; Graham, W.; Dutt, W.; Steinbach, P.; Losordo, T.; Schrader, K.; Main, K. Comparing denitrification rates and carbon sources in commercial scale upflow denitrification biological filters in aquaculture. Aquac. Eng. 2008, 38, 79-92.

23. Davidson, J.; Good, C.; Welsh, C.; Summerfelt, S. The effects of ozone and water exchange rates on water quality and rainbow trout Oncorhynchus mykiss performance in replicated water recirculating systems. Aquac. Eng. 2011, 44, 80-96.

24. Loyless, J.; Malone, R. A sodium bicarbonate dosing methodology for $\mathrm{pH}$ management in freshwater-recirculating aquaculture systems. Prog. Fish Cult. 1997, 59, 198-205.

25. Summerfelt, S.T.; Sharrer, M.J. Design implication of carbon dioxide production within biofilters contained in recirculating salmonid culture systems. Aquac. Eng. 2004, 32, 171-182.

26. Brazil, B.L. Performance and operation of a rotating biological contactor in a tilapia recirculating aquaculture system. Aquac. Eng. 2006, 34, 261-274.

27. Prosser, D.G. Air Driven Rotating Biological Contactor Apparatus. U.S. Patent 3,886,074 A, 27 May 1975.

28. Cortez, S.; Teixeira, P.; Oliveira, R.; Mota, M. Rotating biological contactors: A review on main factors affecting performance. Rev. Environ. Sci. Biotechnol. 2008, 7, 155-172.

29. Ayoub, G.M.; Saikaly, P. The combined effect of step-feed and recycling on RBC performance. Water Res. 2004, 38, 3009-3016.

30. Kamstra, A.; van der Heul, J.; Nijhof, M. Performance and optimisation of trickling filters on eel farms. Aquac. Eng. 1998, 17, 175-192.

31. Malone, R.F.; Beecher, L.E. Use of floating bead filters to recondition recirculating waters in warmwater aquaculture production systems. Aquac. Eng. 2000, 22, 57-73.

32. Summerfelt, S.T. Design and management of conventional fluidized-sand biofilters. Aquac. Eng. 2006, 34, 275-302.

33. Tsukuda, S.; Christianson, L.; Kolb, A.; Saito, K.; Summerfelt, S. Heterotrophic denitrification of aquaculture effluent using fluidized sand biofilters. Aquac. Eng. 2015, 64, 49-59.

34. Timmons, M.B.; Holder, J.L.; Ebeling, J.M. Application of microbead biological filters. Aquac. Eng. 2006, 34, 332-343.

35. Greiner, A.D.; Timmons, M.B. Evaluation of the nitrification rates of microbead and trickling filters in an intensive recirculating tilapia production facility. Aquac. Eng. 1998, 18, 189-200.

36. Rusten, B.; Eikebrokk, B.; Ulgenes, Y.; Lygren, E. Design and operations of the Kaldnes moving bed biofilm reactors. Aquac. Eng. 2006, 34, 322-331.

37. Ödegaard, H. Method and Reactor for Purification of Water. Patent CA 2074470 C, 11 May 1999.

38. Diver, S.; Rinehait, L. Aquaponics-Integration of Hydroponics with Aquaculture; NCAT Agriculture Specialist: Butte, MT, USA, 2010.

39. Lennard, W.A.; Leonard, B.V. A Comparison of Three Different Hydroponic Sub-systems (gravel bed, floating and nutrient film technique) in an Aquaponic Test System. Aquac. Int. 2006, 14, 539-550.

40. Lam, S.S.; Ma, N.L.; Jusoh, A.; Ambak, M.A. Biological nutrient removal by recirculating aquaponic system: Optimization of the dimension ratio between the hydroponic \& rearing tank components. Int. Biodeterior. Biodegrad. 2015, 102, 107-115.

41. Buzby, K.M.; Lin, L.S. Scaling aquaponic systems: Balancing plant uptake with fish output. Aquac. Eng. 2014, 63, 39-44.

42. Endut, A.; Jusoh, A.; Ali, N.; Nik, W.B.W.; Hassan, A. A study on the optimal hydraulic loading rate and plant ratios in recirculation aquaponic system. Bioresour. Technol. 2010, 101, 1511-1517.

43. Lin, Y.F.; Jing, S.R.; Lee, D.Y. The potential use of constructed wetlands in a recirculating aquaculture system for shrimp culture. Environ. Pollut. 2003, 123, 107-113. 
44. Tilley, D.R.; Badrinarayanan, H.; Rosati, R.; Son, J. Constructed wetlands as recirculation filters in large-scale shrimp aquaculture. Aquac. Eng. 2002, 26, 81-109.

45. Kadlec, R.; Wallace, S. Treatment Wetlands, 2nd ed.; Taylor \& Francis Group: New York, NY, USA, 2009.

46. Zhang, S.; Zhou, Q.; Xu, D.; He, F.; Cheng, S.; Liang, W. Vertical-Flow Constructed Wetlands Applied in a Recirculating Aquaculture System for Channel Catfish Culture: Effects on Water Quality and Zooplankton. Pol. J. Environ. Stud. 2010, 19, 1063-1070.

47. Zachritz, W.; Hanson, A.; Sauceda, J.; Fitzsimmons, K. Evaluation of submerged surface flow (SSF) constructed wetlands for recirculating tilapia production systems. Aquac. Eng. 2008, 39, 16-23.

48. Gál, D.; Pekár, F.; Kerepeczki, É.; Váradi, L. Experiments on the operation of a combined aquaculture-algae system. Aquac. Int. 2007, 15, 173-180.

49. Hargreaves, J.A. Photosynthetic suspended-growth systems in aquaculture. Aquac. Eng. 2006, 34, $344-363$.

50. Azim, M.; Little, D. The biofloc technology (BFT) in indoor tanks: Water quality, biofloc composition, and growth and welfare of Nile tilapia (Oreochromis niloticus). Aquaculture 2008, 283, 29-35.

51. Silva, K. Nitrogen and phosphorus dynamics in the biofloc production of the pacific white shrimp, Litopenaeus vannamei. J. World Aquac. Soc. 2013, 44, 30-41.

52. De Schryver, P.; Crab, R.; Defoirdt, T.; Boon, N.; Verstraete, W. The basics of bio-flocs technology: The added value for aquaculture. Aquaculture 2008, 277, 125-137.

53. Furtado, P.S.; Gaona, C.A.P.; Poersch, L.H.; Wasielesky, W. Application of different doses of calcium hydroxide in the farming shrimp Litopenaeus vannamei with the biofloc technology (BFT). Aquac. Int. 2013, 22, 1009-1023.

54. Beveridge, M.; Beveridge, M.; Verdegem, M.; Van Dam, A.A.; Azim, M.E. The potential of fish production based on periphyton. Rev. Fish Biol. Fish. 2002, 12, 1-31.

55. Zhang, S.Y.; Li, G.; Wu, H.B.; Liu, X.G.; Yao, Y.H.; Tao, L.; Liu, H. An integrated recirculating aquaculture system (RAS) for land-based fish farming: The effects on water quality and fish production. Aquac. Eng. 2011, 45, 93-102.

56. Björnsdóttir, R. Mapping Aquaculture Production Systems: A Systematic Literature Review. Master's Thesis, University of Iceland, Reykjavík, Iceland, 2015.

57. Barrut, B.; Blancheton, J.P.; Callier, M.; Champagne, J.Y.; Grasmick, A. Foam fractionation efficiency of a vacuum airlift-Application to particulate matter removal in recirculating systems. Aquac. Eng. 2013, $54,16-21$.

58. Schroeder, J.; Croot, P.; Von Dewitz, B.; Waller, U.; Hanel, R. Potential and limitations of ozone for the removal of ammonia, nitrite, and yellow substances in marine recirculating aquaculture systems. Aquac. Eng. 2011, 45, 35-41.

59. Summerfelt, S.T.; Sharrer, M.J.; Hollis, J.; Gleason, L.E.; Summerfelt, S.R. Dissolved ozone destruction using ultraviolet irradiation in a recirculating salmonid culture system. Aquac. Eng. 2004, 32, 209-223.

60. Gonçalves, A.A.; Gagnon, G.A. Ozone Application in Recirculating Aquaculture System: An Overview. Ozone Sci. Eng. 2011, 33, 345-367.

61. Sharrer, M.J.; Summerfelt, S.T.; Bullock, G.L.; Gleason, L.E.; Taeuber, J. Inactivation of bacteria using ultraviolet irradiation in a recirculating salmonid culture system. Aquac. Eng. 2005, 33, 135-149.

62. Summerfelt, S.T. Ozonation and UV irradiation-An introduction and examples of current applications. Aquac. Eng. 2003, 28, 21-36.

63. Aitcheson, S.; Arnett, J.; Murray, K.; Zhang, J. Removal of aquaculture therapeutants by carbon adsorption. Aquaculture 2000, 183, 269-284.

64. Moreno-Castilla, C. Adsorption of organic molecules from aqueous solutions on carbon materials. Carbon 2004, 42, 83-94.

65. Gutierrez-Wing, M.T.; Malone, R.F. Biological filters in aquaculture: Trends and research directions for freshwater and marine applications. Aquac. Eng. 2006, 34, 163-171.

66. Michaud, L.; Blancheton, J.; Bruni, V.; Piedrahita, R. Effect of particulate organic carbon on heterotrophic bacterial populations and nitrification efficiency in biological filters. Aquac. Eng. 2006, 34, 224-233.

67. True, B.; Johnson, W.; Chen, S. Reducing phosphorus discharge from flow-through aquaculture I: Facility and effluent characterization. Aquac. Eng. 2004, 32, 129-144.

68. Sharrer, M.J.; Rishel, K.; Summerfelt, S. Evaluation of geotextile filtration applying coagulant and flocculant amendments for aquaculture biosolids dewatering and phosphorus removal. Aquac. Eng. 2009, 40, 1-10. 
69. Ebeling, J.; Welsh, C.; Rishel, K. Performance evaluation of an inclined belt filter using coagulation/flocculation aids for the removal of suspended solids and phosphorus from microscreen. Aquac. Eng. 2006, 35, 61-77.

70. Colt, J. Water quality requirements for reuse systems. Aquac. Eng. 2006, 34, 143-156.

71. van Bussel, C.G.; Schroeder, J.P.; Mahlmann, L.; Schulz, C. Aquatic accumulation of dietary metals (Fe, Zn, $\mathrm{Cu}, \mathrm{Co}, \mathrm{Mn}$ ) in recirculating aquaculture systems (RAS) changes body composition but not performance and health of juvenile turbot (Psetta maxima). Aquac. Eng. 2014, 61, 35-42.

72. Rosseland, B.O.; Skogheim, O.K. Neutralization of acidic brook-water using a shell-sand filter or sea-water: Effects on eggs, alevins and smolts of salmonids. Aquaculture 1986, 58, 99-110.

(C) 2016 by the authors; licensee MDPI, Basel, Switzerland. This article is an open access article distributed under the terms and conditions of the Creative Commons Attribution (CC-BY) license (http://creativecommons.org/licenses/by/4.0/). 